\title{
Natural deaths while driving: would screening for risk be ethically justified ?
}

Leo H H Cheng and Richard M Whittington Leeds Dental Institute, Leeds and Coroner's Court, Birmingh商, respectively

\begin{abstract}
Objectives - To determine the epidemiology and the underlying pathological conditions of natural deaths among motor vehicle drivers. Sudden death while driving may cause damage to properties, other vehicles or road users. Although the Medical Commission on Accident Prevention recommended restrictions to drivers at risk of sudden death due to their medical conditions, these restrictions are useless if they do not result in greater safety to the public. Design $-A$ retrospective study of natural deaths of motor vehicle drivers.

Setting - Natural deaths of motor vehicle drivers reported to the coroner for Birmingham and Solihull.

Subjects -86 consecutive natural deaths of motor vehicle drivers in a five-year period between 1984 and 1988.

Results - Of the 86 fatalities reviewed, 80 (93\%) sudden deaths were caused by ischaemic heart disease. Fifty vehicles were involved in collision with 32 properties, 20 other vehicles and six pedestrians. Fifty-one out of 80 cardiac deaths had past cardiac history and three had reported chest pain prior to the sudden death.

Conclusion - An applied normative ethical assessment based on the basic moral principles of autonomy, justice, beneficence and non-maleficence are discussed. We conclude that medical screening of drivers has little benefit for the drivers or other persons.

(Fournal of Medical Ethics 1998;24:248-251)
\end{abstract}

Keywords: Natural death; motor vehicle; drivers; autopsy

\section{Introduction}

Sudden death is often unexpected and dramatic especially when it involves drivers of motor vehicles. Properties and other vehicles may be damaged, and other road users and pedestrians may be injured or killed. In order to ensure public safety and give appropriate advice to drivers with medical disabilities, the Medical Commission on Accident Prevention (MCAP) ${ }^{1}$ has provided updated guidelines to doctors on the medical aspects of fitness to drive since 1968 and recently the Driver and Vehicle Licensing Agency
(DVLA $)^{2}$ has also published a simple guide for medical practitioners. Restrictions recommendg్gd to drivers at risk of sudden death due to their medical condition are useless if they do not resథlt in greater safety to the public.

In order to determine the epidemiology and tife underlying pathological conditions of natural, $N_{0}^{+1}$ contradistinction to traumatic deaths of motor vehicle drivers, we carried out a retrospective study over a five-year period starting in January, 1984. We then looked at the ethical issues reganing possible benefits of restrictions on certain drivers at risk of sudden illness, and the advantages that might follow for themselves \&r others. At no time during our investigation dig ye find that driving itself induced a fatal illiness. Indeed, over the same period, many suche deaths occurring amongst passengers using pub transport were also reported to the coroner.

\section{Material and methods}

The coroner for the Birmingham and Solihall areas serves a population of $1,130,000$ and deaths between January, 1984 and Decemborr, 1988 were studied. During the same five-year period, just over 20,000 unnatural, sudden 9 r cause-unknown deaths were investigated. The data for all 86 cases of sudden natural, nomtraumatic deaths of motor vehicle drivers were obtained from reports provided by the police, wit-

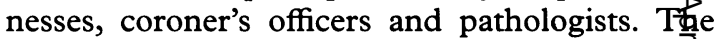
past medical history when known and drug treatments of the deceased were given by the general medical practitioners and relatives. Details of vehicle, types of collision, involvement of othes r road users or street furniture were supplied by tie police. In 75 cases, autopsy was carried out andon 84 instances the matter was dealt with without $\overline{\mathrm{s}} \mathrm{n}$ inquest.

\section{Results}

During the five-year study period, 23,523 dea传s were reported to the coroner for the Birminghâ? and Solihull area. Of those who died of natural causes, 86 were driving a motor vehicle immedi- 
Table 1 Reports concerning natural deaths of drivers of motor vehicles

\begin{tabular}{|c|c|c|c|c|}
\hline Authors (year) country & Total no. & Major cause of death (\%) & Vehicle stopped (\%) & Other road user injured/killed \\
\hline 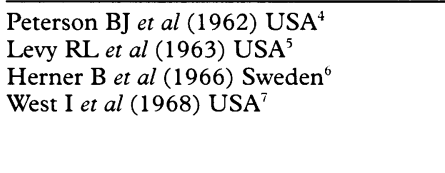 & $\begin{array}{l}81 \\
1 \\
8 \\
155\end{array}$ & $\begin{array}{l}\text { cardiovascular }(80 \%) \\
\text { cardiovascular } \\
\text { cardiovascular }(88 \%) \\
\text { cardiovascular }(94 \%)\end{array}$ & $\begin{array}{l}45(56 \%) \\
\text { not applicable } \\
4(50 \%) \\
\text { not recorded }\end{array}$ & $\begin{array}{l}1 \text { injured (passenger) } \\
6 \text { deaths (passengers) } \\
\text { none } \\
1 \text { death } \\
4 \text { serious } \\
14 \text { minor (passengers) }\end{array}$ \\
\hline $\begin{array}{l}\text { Parsons M (1986) UK } \\
\text { Ostrom B \& Eriksson A (1987) Sweden } \\
\text { Christian MS (1988) UK }{ }^{10} \\
\text { Thomas et al (1988) UK }{ }^{11} \\
\text { Present study (1997) UK }\end{array}$ & $\begin{array}{l}60 \\
76 \\
58 \\
2 \\
86\end{array}$ & $\begin{array}{l}\text { cardiovascular }(43 \%) \\
\text { cardiovascular }(97 \%) \\
\text { cardiovascular }(84 \%) \\
\text { cardiovascular }(100 \%) \\
\text { cardiovascular }(93 \%)\end{array}$ & $\begin{array}{l}49(82 \%) \\
51(67 \%) \\
38(66 \%) \\
\text { not recorded } \\
36(46 \%)\end{array}$ & $\begin{array}{l}3 \text { deaths } \\
2 \text { injured (passengers) } \\
1 \text { death (driver) } \\
\text { not recorded } \\
1 \text { serious } \\
5 \text { minor (pedestrians) }\end{array}$ \\
\hline
\end{tabular}

ately before death. Eighty-five of the deceased were drivers of four-wheeled vehicles, of which ten were heavy goods vehicles, one was a minibus and one was an electric milkfloat. A motorcyclist accounted for one death.

Of all the drivers, $82(95 \%)$ were male, giving a male to female ratio of 20 to 1 . The mean age was 61 years with a range of 26 to 82 years. Impact with other vehicles, property or pedestrians was recorded in $50(58 \%)$ cases. Frontal collision accounted for $46(92 \%)$ cases, side impact for three $(6 \%)$, and rear collision for one $(2 \%)$ case. Only $36(42 \%)$ drivers had managed to stop the vehicle or come safely to a halt without damage.

In the 50 cases of drivers whose vehicles had struck objects on the road, 32 properties, 20 other vehicles and six pedestrians were involved. Of those six pedestrians involved, one was seriously injured and five had minor injuries. Most property and vehicles struck and all pedestrians involved were in frontal collision with the victim's vehicle. Properties struck were trees, walls, fences, buildings or lampposts. Regarding the other impacted vehicle the majority were parked cars at the kerbside. Damage to property and to other vehicles was mostly minor, suggesting a low impact speed and possibly indicative of the drivers' attempts to control their vehicles when suddenly and knowingly becoming unwell. Indeed, some motorists were able to stop, and were found deceased in their stationary vehicles.

Seventy-nine died at the scene or were pronounced dead on arrival at hospital. Of the seven cases who arrived at hospital alive, four died in the accident and emergency department within one hour of arrival and three died from natural causes within ten days of admission to hospital.

Cardiovascular disease was the prime cause of death in 80 (93\%) cases. Triple vessel disease was noted in 71 out of 75 autopsy reports and double vessel disease in four. The mean heart weight was $493 \mathrm{gm}$ with a range of 270 to $725 \mathrm{gm}$. Heart weights greater than $400 \mathrm{gm}$ have been shown to indicate a diseased hypertrophic heart. ${ }^{3}$ Other causes of natural death were respiratory failure, pneumonia, subarachnoid haemorrhage, cerebral infarction, ruptured abdominal aortic aneurysm, and gastrointestinal haemorrhage.

In 29 of the 80 natural deaths due to cardiovascular disease, a past cardiac history was either unknown or unavailable after enquiry with general medical practitioners and relatives. Three drivers experienced chest pain on the same day before driving.

\section{Discussion}

There have been previous reports concerning natural deaths of drivers of motor vehicles and they are listed in table 1 . All these studies identify cardiovascular disease as the major cause of death, which is reflected in our findings. Although thirty-six $(42 \%)$ of drivers in our series stopped the motor vehicle without causing any danger to other road users or damage to roadside furniture, this figure is less than found in other studies. ${ }^{45-10}$ Hence, the frequency of property, vehicles and pedestrians being struck is lower than shown elsewhere. The cost of repair to damaged property and other vehicles can be substantial and injury to six pedestrians in our study was potentially serious, although with one exception they all sustained only minor injuries. Some studies, ${ }^{578}{ }^{10}$ in contrast, have reported deaths of pedestrians, passengers and the driver of the other vehicle involved in a collision.

Is there justification for doctors to interfere? We need to understand the basic ethical principles of autonomy, justice, beneficence and nonmaleficence in order to answer the question. There is a dilemma for doctors, for by exercising beneficence in the interests of public safety a doctor may be breaching the duty of minimising maleficence to the patient who needs to drive. Everybody, including drivers, has the right to manage his or her own autonomy. It might be considered unreasonably and oppressively paternalistic for medical practitioners to make decisions as to who should drive and who should not. 


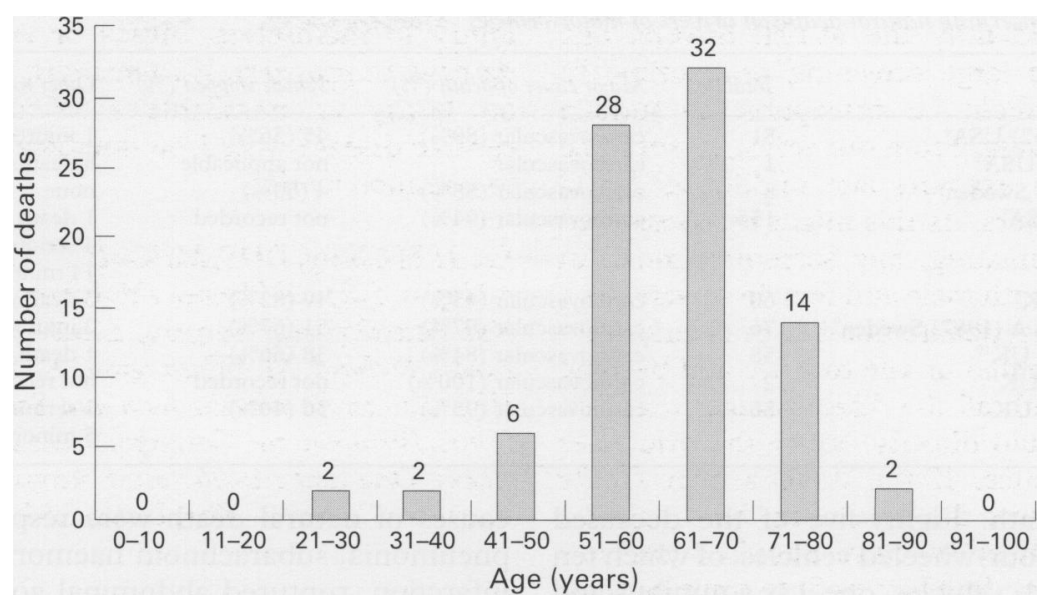

Figure 1 Age distribution of natural deaths among motor vehicle drivers

Would it be excessively zealous and unreasonable to prevent a driver from driving because of ischaemic heart symptoms, which may be the precursor of an accident and so injurious to the driver? However, if such a driver also poses a danger to other road users then the doctor would have a duty to prevent maleficence by the motor vehicle driver. That is the dilemma. Such interference can be justified only if it protects the person, or others, against his or her extreme and unreasonable actions. Thus, in the example of drivers who develop cardiac chest pain prior to driving, doctors have an obligation to warn and discourage such patients, who consult them, from driving, as recommended by the DVLA.

In order to detect those drivers who may pose significant risks to others, one would have to screen the drivers, from our experience, usually elderly, who appear most at risk of sudden illness or death. Unless done thoroughly by clinical examination, backed-up with special investigations, screening will have little value. And even statutory medical screening can be unreliable, as we indicate later. In the face of resource scarcity and competition for medical expertise, challenging problems of distributive justice arise in deciding the appropriate allocation of available finite medical resources. From a utilitarian point of view would it be just to allocate such extensive resources to examining large numbers of drivers and thereby deprive other people of medical care? Should this be done by the driver's own doctor or by another doctor? Should confidential medical findings be sent to the administering authority?

At present, the decision to stop driving on health grounds is one usually made by the individual, though frequently following medical advice. More positive action by the physician is rare and is mostly in relation to daytime epilepsy and a report direct to the DVLA may be justifiged. Indeed the DVLA does advise that a doctor should warn or take other steps to stop the incerrigible patient from driving if suffering from illness likely to lead to a road traffic accident. $\stackrel{\text { क }}{\rightarrow}$

To do good is a desirable goal for all doctors - It is correct for doctors to prevent certain persos from driving who might potentially create o dents with the possibility of harm to propery, other persons or indeed themselves. The prineigle of beneficence is to promote the welfare amd health of patients not only by preventing aps removing harm, but also by balancing benefits and harm in order to promote good. The perceivagle harm in preventing elderly drivers, often wïh known and variable degrees of ischaemic heart disease, from having access to their vehicles is deprive them of the convenience, pleasure a independence that a vehicle provides. This is particularly important in remote suburbia or country areas where there are inadequacies in pubific transport. It is therefore the responsibility of dectors not to inflict unnecessary harm, as recognised in the concept of non-maleficence accordingato the maxim Primum non nocere: Above all (or first) do no harm. ${ }^{12} 13$

For three groups of vehicle drivers it is man tory after they reach the age of forty five to have a medical examination in order to continue hold通g an appropriate licence. We refer to the driversof public service vehicles (PSV), heavy goo ds vehicles (HGV) and public-carrying vehictes $(\mathrm{PCV})$. In our series there were ten drivers of heavy goods vehicles who collapsed when driviong, constituting twelve per cent of the total. The fore, it would seem that their screening examigations and medical certification were far from exact in predicting cardiovascular catastrophe. 
In order to identify the at-risk drivers, one would require a large screening programme to establish who might be susceptible to sudden illness when driving. From our series, it would be most fruitful to examine late middle-aged and elderly male drivers. As this might be considered sexually discriminating, any screening must, in reality, include both male and female drivers. As a result, a disproportionate number of elderly drivers might be deemed unsafe to drive and become house-bound with all the disadvantages that that brings. This would directly violate the principles of non-maleficence. If the driver's own family doctor carried out the screening, he would be placed in an ethical difficulty. Should a patient's personal physician find him unfit to drive because of the remote possibility of an accident, does he deprive him of the independence provided by the use of his motor car?

If a compulsory test, comparable to that undergone by specialist drivers, was to be introduced there might be legal implications. For instance would the doctor be liable for damages if he or she passed a driver as fit who shortly afterwards had a coronary thrombosis and as a result knocked down a pedestrian causing serious injuries? Alternatively, a doctor might consider the elderly person unfit to drive because of evidence of coronary artery disease. However, such people are quite capable of living another twenty years in apparent satisfactory health and they might wish to claim damages from the doctors who had apparently deprived them of the amenity of driving their own personal motor cars.

In our view it would not be realistic or just to attempt to predict those at risk of sudden natural death and thereby prevent them from driving a private motor car on the basis of possibly causing injury to themselves, others or even significant damage to property. Furthermore, to ban drivers on flimsy or unreliable medical evidence of cardiac disease would be unethical and contrary to common justice.

Leo H H Cheng, BDS, MBChB, FDSRCS, FRCS, is a Higher Surgical Trainee (Yorkshire Rotation), Oral and Maxillofacial Surgery, Leeds Dental Institute, Leeds. Richard $M$ Whittington, BMBCh, DMF, is HM Coroner for Birmingham and Solihull, Coroner's Court, Birmingham. Correspondence to: $\mathrm{Mr}$ Leo $\mathrm{H} \mathrm{H}$ Cheng Oral and Maxillofacial Surgery,Leeds Dental Institute, Clarendon Way, Leeds, LS2 9YY.

\section{References}

1 Medical Commission on Accident Prevention. Medical aspects of fitness to drive - a guide for medical practitioners. London: MCAP, 1995.

2 Driver and Vehicle Licensing Agency. For medical practitioners at a glance guide to the current medical standards of fitness to drive. Swansea: DVLA, 1994

3 Polson CJ, Gee J. The essentials of forensic medicine. Oxford: Pergamon Press, 1973.

4 Peterson BJ, Petty CS. Sudden natural death among automobile drivers. Fournal of Forensic Science 1962; 7:274-85.

5 Levy RL, Chappelle CE, Richards DW. Heart disease in drivers of public motor vehicles as a cause of highway accidents. fournal of the American Medical Association 1963;184:481-4.

6 Herner B, Smedby B, Ysander L. Sudden illness as a cause of motor-vehicle accidents. British fournal of Industrial Medicine $1966 ; 23: 37-41$

7 West I, Nielsen GL, Gilmore AE, Ryan JR. Natural death at the wheel. Fournal of the American Medical Association 1968; 205:266-71

8 Parsons $M$. Fits and other causes of loss of consciousness while driving. Quarterly fournal of Medicine 1986;277:295-303.

9 Ostrom M, Eriksson A. Natural death while driving. Fournal of Forensic Science 1987;32: 988-98.

10 Christian MS. Incidence and implications of natural deaths of road users. British Medical fournal 1988;297:1021-4.

11 Thomas AC, Knapman PA, Krikler DM, Davies MJ. Community study of the causes of "natural" sudden death. British Medical Fournal 1988;297:1453-6.

12 Beauchamp TL, Childress JF. Principles of biomedical ethics. Oxford: Oxford University Press, 1989.

13 Garrett TM, Baillie HW, Garrett RM. Health care ethics - principles and problems. New Jersey: Prentice Hall, 1993. 